\section{Kidney \\ Blood Pressure Research}

\title{
Depression and Quality of Life in Relation to Decreased Glomerular Filtration Rate Among Adults with Hypertension in Rural Northeast China
}

\author{
Xiaofan Guo ${ }^{a}$ Zhao Lia Shasha Yu Hongmei Yang ${ }^{\mathrm{a}}$ Liang Guo \\ Liqiang Zheng $^{b}$ Luoning Zhuc ${ }^{c}$ Yonghong Zhang ${ }^{d}$ Yingxian Sun ${ }^{a}$
}

\begin{abstract}
${ }^{a}$ Department of Cardiology, the First Hospital of China Medical University; ${ }^{b}$ Department of Clinical Epidemiology, Library, Shengjing Hospital of China Medical University, Shenyang, Liaoning; 'Department of Cardiology, Dongfang Hospital affiliated to Tongji University, Shanghai; 'Department of Epidemiology, School of Public Health, Medical College of Soochow University, Suzhou, Jiangsu, People's Republic of China
\end{abstract}

\section{Key Words}

Chronic kidney disease $\cdot$ Depression $\cdot$ Glomerular filtration rate $\cdot$ Hypertension quality of life

\begin{abstract}
Background/Aims: We aim to investigate the extent to which depression and quality of life might be associated with decreased glomerular filtration rate (GFR) in a large hypertensive population in rural Northeast China. Methods: A total of 5566 hypertensive participants aged 35 years and older were screened with a stratified cluster multistage sampling scheme in rural areas of Liaoning Province during 2012-2013. Decreased GFR was defined as estimated GFR $<60 \mathrm{ml} / \mathrm{min} / 1.73 \mathrm{~m}^{2}$. Results: The overall prevalence of decreased GFR was $3.2 \%$. In the multivariable regression model, participants with moderate or greater depression had a greater risk for having a decreased GFR (OR: $1.739,95 \% \mathrm{CI}: 1.004$ to 3.014) after full adjustment. Every 1-point increase of all the domains in WHOQOL-BREF, except for physical and environment domains, was significantly related to a lower risk for decreased GFR adjusting for age, gender and race. However, after fully adjustment, only social relations remained significant (OR: 0.899, 95\%CI: 0.820 to 0.985 ). Increasing in total scores of WHOQOL-BREF was a protective factor against decreased GFR after fully adjustment. Conclusion: We found that moderate or greater depression and lower quality of life were associated with higher risks for developing decreased GFR.
\end{abstract}

Yingxian Sun, MD, PhD

KARGER 125
Department of Cardiology, the First Hospital of China Medical University, 155 Nanjing North Street, Heping District, Shenyang 110001 (People's Republic of China)

Tel. +86 24 83282688, Fax +86 24 83282346, E-Mail yxsun@mail.cmu.edu.cn 


\section{Kidney Blood Pressure Research}

\section{Introduction}

The increasing prevalence of chronic kidney disease (CKD) has become a worldwide public health problem [1]. It has been demonstrated that even minor degrees of renal dysfunction were associated with an enhanced cardiovascular (CV) risk [2-3]. Among hypertensive patients, CKD is much more prevalent [4-6] and is a risk factor for CV events and all-cause mortality [7-9]. Guidelines for the management of hypertension have recognized the relevance of albuminuria and decreased estimated glomerular filtration rate (eGFR) on $\mathrm{CV}$ prognosis in hypertensive patients $[10,11]$. Considering the large base of hypertensive patients, more attention should be paid to CKD in this population.

In recent years, the Quality of life (QoL) and depression status in patients with CKD have received growing interest. It is evidenced that depression was prevalent and QoL was lower among CKD patients [12-16]. Several studies linked depression or low QoL to increased mortality risk in CKD patients [17-19], indicating the importance and potential effects of depression and QoL during CKD.

Although the treatment for the patients who have already developed CKD is crucial, it is more practical and cost-effective to prevent CKD before it happens, especially in hypertensive patients. To achieve the prevention, comprehensive identification of its risk factors becomes first step to take. To date, there is little information on depression or QoL as risk factors for CKD. Given the evidence on depression and QoL in relation to CKD, we hypothesized that depression and QoL were independent predictors for developing CKD. Therefore, we performed this study to examine the extent to which depression and QoL might be associated with decreased GFR in a large hypertensive population in rural Northeast China.

\section{Subjects and Methods}

\section{Study Population}

Liaoning Province is located in Northeast China. From January 2012 to August 2013, a representative sample aged $\geq 35$ years was selected to describe the prevalence, incidence and natural history of cardiovascular risk factors in rural areas of Liaoning Province. The study adopted a multi-stage, stratified randomly cluster-sampling scheme. In the first stage, 3 counties (Dawa, Zhangwu, and Liaoyang County) were selected from the eastern, southern, and Northern region of Liaoning province. In the second stage, one town was randomly selected from each county (a total of 3 towns). In the third stage, 8-10 rural villages from each town were randomly selected (a total of 26 rural villages). Participants with pregnancy, malignant tumor and mental disorder were excluded from the present study. All the eligible permanent residents aged $\geq 35$ years from each village were invited to attend the study, with a response rate of $85.3 \%$. The study was approved by the Ethics Committee of China Medical University (Shenyang, China). All procedures were performed in accordance with the ethical standards. Written consent was obtained in all participants after they had been informed of the objectives, benefits, medical items and confidentiality agreement of personal information. If the participants were illiterate, we obtained the written informed consents from their proxies. In this report, a total of 6077 patients with hypertension were selected. Only participants with a complete set of data regarding the variables analyzed in the present study were included, making a final sample size of 5566 (2730 males and 2836 females).

\section{Depressive Symptoms}

Depressive symptoms were assessed using the Patient Health Questionnaire (PHQ-9), which is a 9-item screening instrument with high reliability and validity in the primary care population [20, 21]. Participants were asked how often, over the past 2 weeks, they had been bothered by each of the depressive symptoms with scores ranging from 0 to 27 . The severity of depressive disorder is considered mild for scores ranging from 5 to 10, moderate for scores of 10 to 14, moderately severe for scores of 15-19 and severe for scores of 20-27. A PHQ-9 score $\geq 10$ has been recommended as the cut-off score for detecting major depressive disorders $[20,22]$. 


\section{Kidney \\ Blood Pressure Research}

\begin{tabular}{l|l}
\hline Kidney Blood Press Res 2015;40:31-40 \\
\hline \begin{tabular}{l|l} 
DOI: 10.1159/000368480 & (C) 2015 S. Karger AG, Basel \\
Publisned online: February 07, 2015 & ww.karger.com/kbr \\
\hline
\end{tabular}
\end{tabular}

Guo et al.: Depression and Quality of Life

Quality of Life

The quality of life was measured with the World Health Organization Quality of Life Brief Scale (WHOQOL-BREF) [23] which is a self-report inventory with 26 original items. The items fall into four domains: the physical health (7 items), the psychological health (6 items), the social relationships (3 items) and the environment (8 items), together with 2 items measuring overall QoL and general health [24]. The scale has demonstrated good internal consistency with Cronbach's alpha ranging from 0.67-0.81 for each domain. Each item is answered on a 5-point response scale, and the range of scores is form 4 to 20 after calculation, with higher scores indicating better QoL.

Glomerular Filtration Rate Assessment

Fasting blood samples were collected in the morning after at least $12 \mathrm{~h}$ of fasting for all participants. Blood samples were obtained from an antecubital vein into vacutainer tubes containing EDTA. Blood chemical analyses were performed at a central, certified laboratory. Serum creatinine (SCr) was measured enzymatically on an autoanalyzer. GFR was estimated using the equation originating from the CKD Epidemiology Collaboration (CKD-EPI) equation [25], which is more appropriate than the Modification of Diet in Renal Disease (MDRD) Study group equation [26]. Decreased GFR was defined as estimated GFR (eGFR) $<60 \mathrm{ml} / \mathrm{min} / 1.73 \mathrm{~m}^{2}$.

\section{Covariate Measurements}

Information on covariates, such as demographic characteristics, lifestyle risk factors, dietary habits, family income and medical history of hypertension, were collected during a single clinic visit by cardiologists and trained nurses using a standard questionnaire by face-to-face interview. Before the survey was performed, we invited all eligible investigators to attend the organized training. The training contents included the purpose of this study, how to administer the questionnaire, the standard method of measurement, the importance of standardization, and the study procedures. A strict test was evaluated after this training, only those who scored perfectly on the test could become investigators. During data collection, our inspectors had further instructions and support.

According to American Heart Association protocol, blood pressure was measured three times at 2-min intervals after at least 5 min of rest using a standardized automatic electronic sphygmomanometer (HEM907; Omron), which had already been validated according to the British Hypertension Society protocol [27]. The participants were advised to avoid caffeinated beverages and exercise for at least 30 min before the measurement. During the measurement, the participants were seated with the arm supported at the level of the heart. The mean of three BP measures was calculated and used in all analyses.

Weight and height were measured to the nearest $0.1 \mathrm{~kg}$ and $0.1 \mathrm{~cm}$ respectively with the participants in light weight clothing and without shoes. Waist circumference (WC) was measured at the umbilicus using a non-elastic tape (to the nearest $0.1 \mathrm{~cm}$ ), with the participants standing at the end of normal expiration. Body mass index (BMI) was calculated as weight in kilograms divided by the square of the height in meters.

Fasting plasma glucose (FPG), total cholesterol (TC), low-density lipoprotein cholesterol (LDL-C), high-density lipoprotein cholesterol (HDL-C), triglyceride (TG), uric acid, hemoglobin and other routine blood biochemical indexes were analyzed enzymatically on an autoanalyzer. All laboratory equipment was calibrated and blinded duplicate samples were used.

Physical activity included occupational and leisure-time physical activity. A detailed description of the methods has been presented elsewhere [28]. Occupational and leisure-time physical activity were merged and regrouped into low, moderate and high levels. Educational level was divided into primary school or below, middle school and high school or above. Family income was classified as $\leq 5000,5000-20000$ and $>20000 \mathrm{CNY} /$ year. Self-reported sleep duration (including nocturnal and nap duration) was obtained from the questionnaire.

The dietary pattern was assessed using recall of foods eaten in the previous year. The questionnaire included questions on the average consumption of several food items per week. The reported consumption was quantified approximately in terms of grams per week. A special diet score (vegetable consumption score plus meat consumption score) was calculated for each participant (range 0-6). Higher values of the diet score indicate higher meat consumption and lower vegetable consumption and greater adherence to a 


\section{Kidney \\ Blood Pressure Research}

Kidney Blood Press Res 2015;40:31-40

DOI: 10.1159/000368480

Publisned onine: February 07, 2015

(C) 2015 S. Karger AG, Basel

www.karger.com/kbr

Table 1. Baseline characteristics of study population

\begin{tabular}{|c|c|c|c|c|}
\hline \multirow{2}{*}{ Variables } & \multirow{2}{*}{ All $(n=5566)$} & \multicolumn{2}{|c|}{ Estimated GFR $\left(\mathrm{ml} / \mathrm{min} / 1.73 \mathrm{~m}^{2}\right)$} & \multirow{2}{*}{$P$-value } \\
\hline & & $\geq 60(n=5388)$ & $<60(n=178)$ & \\
\hline Age (year) & $57 \pm 10$ & $57 \pm 10$ & $69 \pm 9$ & $<0.001$ \\
\hline Male gender (\%) & $2730(49.0)$ & $2664(49.4)$ & $66(37.1)$ & 0.001 \\
\hline Race of Han (\%) & $5265(94.6)$ & $5090(94.5)$ & $175(98.3)$ & 0.026 \\
\hline Spouse (live, \%) & 5027 (90.3) & $4892(90.8)$ & $135(75.8)$ & $<0.001$ \\
\hline Current smoking status (\%) & $1953(35.1)$ & $1906(35.4)$ & $47(26.4)$ & 0.014 \\
\hline Current drinking status (\%) & $1369(24.6)$ & $1357(25.2)$ & $12(6.7)$ & $<0.001$ \\
\hline Education (\%) & & & & $<0.001$ \\
\hline Primary school or below & $3087(55.5)$ & $2950(54.8)$ & $137(77.0)$ & \\
\hline Middle school & $1987(35.7)$ & $1953(36.2)$ & $34(19.1)$ & \\
\hline High school or above & $492(8.8)$ & $485(9.0)$ & $7(3.9)$ & \\
\hline Physical activity (\%) & & & & $<0.001$ \\
\hline Low & $1862(33.5)$ & $1744(32.4)$ & $118(66.3)$ & \\
\hline Moderate & $3376(60.7)$ & $3322(61.7)$ & $54(30.3)$ & \\
\hline High & $328(5.9)$ & $322(6.0)$ & $6(3.4)$ & \\
\hline Family income (CNY/year, \%) & & & & $<0.001$ \\
\hline$\leq 5000$ & $847(15.2)$ & $796(14.8)$ & $51(28.7)$ & \\
\hline $5000-20000$ & $3123(56.1)$ & $3039(56.4)$ & $84(47.2)$ & \\
\hline$>20000$ & $1596(28.7)$ & $1553(28.8)$ & $43(24.2)$ & \\
\hline Diet score & $2.3 \pm 1.1$ & $2.3 \pm 1.1$ & $1.9 \pm 1.0$ & $<0.001$ \\
\hline Sleep duration $(\mathrm{h} / \mathrm{d})$ & $7.2 \pm 1.8$ & $7.3 \pm 1.8$ & $6.6 \pm 1.9$ & $<0.001$ \\
\hline SBP (mmHg) & $158.7 \pm 19.6$ & $158.5 \pm 19.5$ & $165.1 \pm 22.2$ & $<0.001$ \\
\hline DBP(mmHg) & $88.9 \pm 11.2$ & $88.9 \pm 11.0$ & $88.1 \pm 14.9$ & 0.152 \\
\hline BMI $\left(\mathrm{kg} / \mathrm{m}^{2}\right)$ & $25.6 \pm 3.7$ & $25.6 \pm 3.7$ & $25.4 \pm 3.7$ & 0.339 \\
\hline WC $(\mathrm{cm})$ & $84.9 \pm 9.7$ & $84.9 \pm 9.7$ & $85.9 \pm 10.4$ & 0.232 \\
\hline TC $(\mathrm{mmol} / \mathrm{L})$ & $5.4 \pm 1.1$ & $5.4 \pm 1.1$ & $5.9 \pm 1.6$ & $<0.001$ \\
\hline TG (mmol/L) & $1.8 \pm 1.6$ & $1.8 \pm 1.6$ & $2.2 \pm 1.7$ & $<0.001$ \\
\hline LDL-C (mmol/L) & $3.1 \pm 0.9$ & $3.1 \pm 0.9$ & $3.3 \pm 1.1$ & 0.005 \\
\hline HDL-C (mmol/L) & $1.4 \pm 0.4$ & $1.4 \pm 0.4$ & $1.3 \pm 0.4$ & $<0.001$ \\
\hline FPG (mmol/L) & $6.2 \pm 1.9$ & $6.1 \pm 1.9$ & $6.5 \pm 2.2$ & 0.087 \\
\hline Uric acid (umol/L) & $302.2 \pm 87.8$ & $298.7 \pm 84.8$ & $406.2 \pm 110.9$ & $<0.001$ \\
\hline Hemoglobin (g/L) & $140.8 \pm 18.2$ & $141.1 \pm 18.0$ & $130.9 \pm 20.4$ & $<0.001$ \\
\hline Estimated GFR $\left(\mathrm{ml} / \mathrm{min} / 1.73 \mathrm{~m}^{2}\right)$ & $90.1 \pm 15.4$ & $91.5 \pm 13.4$ & $48.5 \pm 12.4$ & $<0.001$ \\
\hline Antihypertensive medication (\%) & $1419(25.5)$ & $1333(24.7)$ & $86(48.3)$ & $<0.001$ \\
\hline History of heart disease (\%) & $1045(18.8)$ & $971(18.0)$ & $74(41.6)$ & $<0.001$ \\
\hline History of stroke (\%) & $738(13.3)$ & $689(12.8)$ & $49(27.5)$ & $<0.001$ \\
\hline Moderate or greater Depression (\%) & $375(6.7)$ & $340(6.3)$ & $35(19.7)$ & $<0.001$ \\
\hline \multicolumn{5}{|c|}{$\begin{array}{l}\text { Data are expressed as the mean } \pm \text { SD or as n (\%). } \\
\text { Abbreviations: GFR, glomerular filtration rate; CNY, China Yuan (1CNY=0.161 USD); SBP, systolic blood } \\
\text { pressure; DBP, diastolic blood pressure; BMI, body mass index; WC, waist circumference; TC, total } \\
\text { cholesterol; TG, triglyceride; LDL-C, low-density lipoprotein cholesterol; HDL-C, high-density lipoprotein } \\
\text { cholesterol; FPG, fasting plasma glucose. }\end{array}$} \\
\hline
\end{tabular}

Westernized diet, while lower values indicate adherence to the Chinese-diet. Similar methods for calculating diet score could be found in ATTICA study [29].

\section{Statistical Analysis}

Descriptive statistics were calculated for all the variables, including continuous variables (reported as mean values and standard deviations) and categorical variables (reported as numbers and percentages). Differences among categories were evaluated using Student's t-test, ANOVA, non-parametric test or the $\chi 2$ test as appropriate. Multivariate logistic regression analyses were used to identify independent associations between depression or QoL and decreased GFR in different models with odds ratios (ORs) and corresponding 95\% confidence intervals (CIs) calculated. Model 1 was adjusted for age, gender and race; model 2 was 


\section{Kidney Blood Pressure Research}

Kidney Blood Press Res 2015;40:31-40

DOI: 10.1159/000368480

Publisnea onlıne: Fedruary 07, 2015

C 2015 S. Karger AG, Base

www.karger.com/kbr

Table 2. The mean scores of PHQ-9 and WHOQOL-BREF based on estimated GFR category

\begin{tabular}{ccccccc}
\hline & \multirow{2}{*}{ All $(\mathrm{n}=5566)$} & \multicolumn{4}{c}{ Estimated GFR $\left(\mathrm{ml} / \mathrm{min} / 1.73 \mathrm{~m}^{2}\right)$} & $\begin{array}{c}P- \\
\text { value }\end{array}$ \\
\cline { 3 - 6 } & & $\geq 90(\mathrm{n}=3019)$ & $60-90(\mathrm{n}=2369)$ & $45-60(\mathrm{n}=134)$ & $<45(\mathrm{n}=44)$ & \\
PHQ-9 & & & & & & \\
All participants & $3.17 \pm 3.86$ & $2.86 \pm 3.64$ & $3.42 \pm 3.95$ & $4.74 \pm 5.05$ & $6.14 \pm 5.71$ & $<0.001$ \\
$\quad$ No depression & $1.32 \pm 1.41$ & $1.27 \pm 1.41$ & $1.40 \pm 1.42$ & $1.29 \pm 1.42$ & $1.10 \pm 1.52$ & 0.009 \\
$\quad$ Mild depression & $6.56 \pm 1.37$ & $6.49 \pm 1.34$ & $6.62 \pm 1.39$ & $6.42 \pm 1.43$ & $7.21 \pm 1.48$ & 0.141 \\
Moderate or greater depression & $13.63 \pm 3.76$ & $13.78 \pm 4.10$ & $13.47 \pm 3.53$ & $13.40 \pm 3.49$ & $14.70 \pm 2.87$ & 0.47 \\
$\quad$ WHOQOL-BREF & & & & & & \\
Overall quality of life & $3.26 \pm 0.68$ & $3.29 \pm 0.68$ & $3.23 \pm 0.68$ & $3.11 \pm 0.60$ & $2.89 \pm 0.66$ & $<0.001$ \\
$\quad$ General health & $3.30 \pm 0.86$ & $3.37 \pm 0.84$ & $3.26 \pm 0.87$ & $2.96 \pm 0.90$ & $2.50 \pm 0.93$ & $<0.001$ \\
$\quad$ Physical health & $12.69 \pm 1.58$ & $12.91 \pm 1.53$ & $12.49 \pm 1.59$ & $12.00 \pm 1.80$ & $11.51 \pm 1.49$ & $<0.001$ \\
Psychological health & $12.71 \pm 1.86$ & $12.93 \pm 1.76$ & $12.52 \pm 1.93$ & $11.80 \pm 1.93$ & $11.29 \pm 1.67$ & $<0.001$ \\
Social relationships & $14.49 \pm 2.09$ & $14.84 \pm 1.94$ & $14.15 \pm 2.17$ & $13.13 \pm 2.29$ & $12.94 \pm 1.81$ & $<0.001$ \\
$\quad$ Environment & $13.44 \pm 2.08$ & $13.47 \pm 2.02$ & $13.45 \pm 2.14$ & $12.92 \pm 2.27$ & $12.30 \pm 1.97$ & $<0.001$ \\
$\quad$ Total scores & $59.90 \pm 7.00$ & $60.80 \pm 6.64$ & $59.09 \pm 7.19$ & $55.92 \pm 7.55$ & $53.42 \pm 6.45$ & $<0.001$ \\
\hline
\end{tabular}

Data are expressed as the mean \pm SD.

Abbreviations: GFR, glomerular filtration rate; PHQ, Patient Health Questionnaire; WHOQOL-BREF, the World Health

Organization Quality of Life Brief Scale.

adjusted for factors in model 1 plus education level, family income, marital status, dietscore, sleep duration, current smoking and drinking status and physical activity; and model 3 was adjusted further for BMI, WC, systolic blood pressre (SBP), diastolic blood pressre (DBP), TC, TG, LDL-C, HDL-C, FPG, uric acid, hemoglobin, antihypertensive medication, history of heart disease and stroke. Depression status and general QoL were adjusted when analyzing each other in all three models. All the statistical analyses were performed using SPSS version 17.0 software, and $P$ values less than 0.05 were considered to be statistically significant.

\section{Results}

A total of 5566 participants (2730 males and 2836 females) were included in the present study with a mean age of $57 \pm 10$ years. The overall prevalence of decreased GFR (eGFR<60 $\mathrm{ml} / \mathrm{min} / 1.73 \quad \mathrm{~m}^{2}$ ) was $3.2 \%$. There were 375 participants presenting moderate or greater depression. The ethnic composition of the population was predominantly Han Chinese (94.6\%).

Table 1 presents baseline characteristics of the studied population. Participants with eGFR $<60 \mathrm{ml} / \mathrm{min} / 1.73 \mathrm{~m}^{2}$ were more likely to be female, older and Han ethnic compared to those with $\mathrm{eGFR} \geq 60 \mathrm{ml} / \mathrm{min} / 1.73 \mathrm{~m}^{2}$ (all $\mathrm{P}<0.05$ ). A lower proportion of current smoking and drinking status was observed in the participants with eGFR $<60 \mathrm{ml} / \mathrm{min} / 1.73 \mathrm{~m}^{2}$. The mean levels of SBP, TC, TG, LDL-C, FPG and uric acid were significantly higher in the group of decreased GFR. More participants in the group of eGFR $<60 \mathrm{ml} / \mathrm{min} / 1.73 \mathrm{~m}^{2}$ had a history of heart disease or stroke and moderate or greater depression.

Table 2 describes the scores of PHQ-9 and WHOQOL-BREF according to eGFR category. The mean scores of PHQ-9 and total WHOQOL-BREF were $3.2 \pm 3.9$ and $59.9 \pm 7.0$, respectively. As eGFR decreased, scores of PHQ-9 increased and scores for total and every domain of WHOQOL-BREF decreased significantly. Figure 1 shows the total WHOQOL-BREF scores 


\section{Kidney Blood Pressure Research}

Kidney Blood Press Res 2015;40:31-40

DOI: $10.1159 / 000368480$

Publisned onine: February 07, 2015

C 2015 S. Karger AG, Base

www.karger.com/kbr

Table 3. Multivariable logistic regression analyses for associations between depression or quality of life and decreased glomerular filtration rate

\begin{tabular}{cccccccccc}
\hline & \multicolumn{3}{c}{ Model 1 } & & & Model 2 & \multicolumn{2}{c}{ Model 3 } \\
\cline { 2 - 8 } & OR & $95 \% \mathrm{CI}$ & $P$-value & OR & $95 \% \mathrm{CI}$ & $P$-value & OR & $95 \% \mathrm{CI}$ & $P$-value \\
\hline $\begin{array}{c}\text { Moderate or greater depression (yes/no) } \\
\text { Quality of life (every 1-point increase) }\end{array}$ & 1.836 & $1.175-2.867$ & 0.008 & 1.666 & $1.063-2.611$ & 0.026 & 1.739 & $1.004-3.014$ & 0.048 \\
Overall quality of life & & & & & & & & \\
$\quad$ General health & 0.755 & $0.590-0.965$ & 0.025 & 0.784 & $0.609-1.011$ & 0.061 & 0.789 & $0.580-1.072$ & 0.13 \\
Physical health & 0.586 & $0.486-0.707$ & $<0.001$ & 0.634 & $0.524-0.768$ & $<0.001$ & 0.817 & $0.646-1.034$ & 0.092 \\
Psychological health & 0.912 & $0.823-1.011$ & 0.08 & 0.952 & $0.857-1.058$ & 0.361 & 0.979 & $0.862-1.112$ & 0.746 \\
Social relationships & 0.853 & $0.781-0.931$ & $<0.001$ & 0.863 & $0.789-0.944$ & 0.001 & 0.904 & $0.813-1.005$ & 0.063 \\
$\quad$ Environment & 0.866 & $0.804-0.933$ & $<0.001$ & 0.877 & $0.812-0.948$ & 0.001 & 0.899 & $0.820-0.985$ & 0.023 \\
Total scores & 0.947 & $0.874-1.025$ & 0.179 & 0.948 & $0.873-1.030$ & 0.209 & 0.943 & $0.856-1.040$ & 0.24 \\
& 0.952 & $0.929-0.975$ & $<0.001$ & 0.957 & $0.933-0.982$ & 0.001 & 0.967 & $0.938-0.998$ & 0.034 \\
\hline
\end{tabular}

Model 1: adjusted for age, gender and race.

Model 2: adjusted for factors in model 1 and education level, family income, marital status, dietscore, sleep duration, current smoking and drinking status, and physical activity.

Model 3: adjusted for factors in model 2 and body mass index, waist circumference, systolic blood pressure, diastolic blood pressure, total cholesterol, triglyceride, low-densitylipoprotein cholesterol, high-density lipoprotein cholesterol, fasting plasma glucose, uric acid, hemoglobin, antihypertensive

medication, and history of heart disease and stroke.

In the analysis for depression, general quality of life was adjusted and in the analysis for quality of life, depression status was adjusted.

Moderate or greater depression defined as PHQ- 9 score $\geqslant 10$.

Abbreviations: $\mathrm{OR}$, odds ratio; $95 \% \mathrm{CI}, 95 \%$ confidence interval.

according to quartiles of PHQ-9 scores. The scores of QoL were significantly reduced in the upper quartiles of depression scores in both groups of eGFR $<60$ and $\geq 60 \mathrm{ml} / \mathrm{min} / 1.73 \mathrm{~m}^{2}$ (both $\mathrm{P}<0.001$ ).

Figure 2 presents the prevalence of decreased GFR according to quartiles of PHQ-9 and WHOQOL-BREF scores. Upper quartiles of PHQ-9 had higher prevalence of decreased GFR $(\mathrm{P}<0.001)$. A decreasing trend of the prevalence was observed as the scores for QoL in-

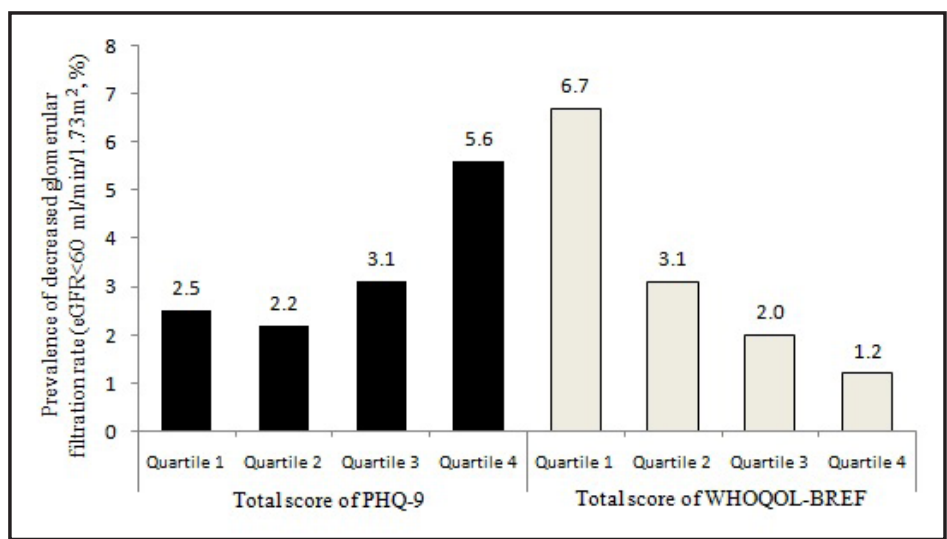

Fig. 2. Prevalence of decreased glomerular filtration rate $(\mathrm{eGFR}<60$ $\mathrm{ml} / \mathrm{min} / 1.73 \mathrm{~m}^{2}$ ) according to quartiles of PHQ-9 and WHOQOL-BREF scores. eGFR: estimated glomerular filtration rate; PHQ-9: Patient Health Questionnaire-9; WHOQOL-BREF: World Health Organization Quality of Life Brief Scale. creased $(\mathrm{P}<0.001)$.

Table 3 presents multivariable logistic regression analyses on the associations between depression and QoL scores and decreased GFR. Moderate or greater depression (PHQ$9 \geq 10$ ) was associated with a higher risk of decreased GFR (eGFR $<60 \mathrm{ml} / \mathrm{min} / 1.73 \mathrm{~m}^{2}$ ) in all three models. After adjusted for age, gender, race, lifestyle factors, clinical correlates and general quality of life, participants with moderate or greater depression had a 1.7-fold risk for having a decreased GFR (OR: 1.739, 95\%CI: 1.004 to 3.014). Every 1-point increase of all the elements in WHOQOL-BREF, except for physical and environment domains, was significantly related to a lower risk for decreased GFR in model 1 . However, after fully adjustment, only social relations remained significant (OR: 0.899, 95\%CI: 0.820 to 0.985 ). Increasing in total scores of WHOQOL-BREF was a protective factor against decreased GFR in all three models. 


\section{Kidney Blood Pressure Research}

\section{Discussion}

To our knowledge, this is the first evaluation of the relationship between depressive symptoms and QoL and kidney disease in a large Chinese hypertensive population. We found that moderate or greater depression increased approximately 1.7-fold risk of developing decreased GFR and higher scores in social relationships and total scores of QoL were significantly associated with lower risks of decreased GFR after fully adjusted for confounders, adding evidence for primary prevention of CKD in hypertensive patients.

Several studies investigated the prevalence of CKD in non-Asian hypertensive populations, with rates for decreased GFR (eGFR $<60 \mathrm{ml} / \mathrm{min} / 1.73 \mathrm{~m}^{2}$ ) raging from around 10\%-30\% [5, 30]. The prevalence of decreased GFR we found in Chinese hypertensives was twice as that in general Chinese population [31], though lower than that found in western populations. It is suggested that a much higher number of individuals are at risk of developing CKD when the number of patients with hypertension is taken into account [32], highlighting the significance of preventing CKD in hypertensive population. However, risk factors for developing CKD in hypertensives evaluated by previous studies were confined to traditional correlates, such as blood pressure and lipid disorder.

Although the association between depression and clinical outcomes in patients with CKD were well documented [18,33], studies focusing on the role of depression as a factor for primary prevention of CKD were rare, especially in hypertensive group. In our study, we found that moderate or greater depression increased the risk for developing decreased GFR in hypertensive patients. Since depression status and QoL had influences on each other, we adjusted one of them when analyzing the other. The mechanism under the positive association between depression and decreased GFR after fully adjustment was unknown. The low threshold to stress, pain and physical activity caused by disturbance of the serotonergic and noradrenergic pathway in depression might serve as one part of the puzzle [34]. In addition, poverty was one of the most significant correlates for major depressive disorder $[35,36]$, and higher prevalence of reduced eGFR was observed in sites with low economic development [31]. Therefore, it is reasonable to assume that family income might play a role in the correlation between depression and decreased GFR. The effect of family income have been investigated in many previous studies conducted in CKD patients [37, 38], but limited information for the primary prevention of CKD is available. However, in the present study, we failed to find a positive role of family income in the association between depression and decreased GFR after further analysis by stratification of the variable. More studies are expected to investigate this issue. It was also explained that depression was correlated with unhealthy behaviors, such as smoking and drinking, but we had them adjusted in the analyses.

We chose the WHOQOL-BREF to evaluate QoL in the present study because it includes physical, psychological, social relationships and environment domains, the last two of which are more special than other measures of QoL, such Short Form Health Survey (FS36). Social relationships and environment are frequently affected by policies and cultures, thus WHOQOL-BREF may provide better perspectives of living status in which policies and cultures are taken into consideration. Our study found that increasing in total scores of QoL was associated with a lower risk for decreased GFR, indicating that maintaining or improving QoL should be an important consideration in preventing CKD among hypertensives. Evidence suggested that social support had effects on clinical outcomes in various chronic diseases [39]. In the present study, we found that social relationship was a protective factor for having decreased GFR. The potential mechanism was unexplained. Further researches are needed to explore the mechanisms underlying.

Some limitations should be considered in light of these results. First, the sample in the present study was drawn from a single geographic area, thus data are not representative of population throughout China. Second, urinary albumin was not measured in our study and there might be other unmeasured confounding variables, which could compromise our 


\section{Kidney \\ Blood Pressure Research}

Guo et al.: Depression and Quality of Life

results. In addition, our results were based on a cross-sectional design, thus no cause-andeffect relationships could be established.

\section{Conclusion}

In this large Chinese hypertensive population, a population not previously evaluated in the literature and carries a high burden of kidney disease, we found that moderate or greater depression and lower quality of life, especially the aspect of social relationship, were associated with higher risks for developing decreased GFR after adjusting potential confounders. During daily management of hypertension, psychological status and quality of life should be considered to prevent CKD in the hypertensive population.

\section{Disclosure Statement}

None

\section{Acknowledgements}

This study was supported by grants from the "Twelfth Five-Year" project

funds (National Science and Technology Support Program of China, Grant \#2012BA J18B02) and the Social Development Research Program of Liaoning Province (201322 5089).

\section{References}

-1 Dirks JH, de Zeeuw D, Agarwal SK, Atkins RC, Correa-Rotter R, D'Amico G, Bennett PH, El Nahas M, Valdes RH, Kaseje D, Katz IJ, Naicker S, Rodriguez-Iturbe B, Schieppati A, Shaheen F, Sitthi-Amorn C, Solez K, Viberti G, Remuzzi G, Weening JJ; International Society of Nephrology Commission for the Global Advancement of Nephrology Study Group 2004: Prevention of chronic kidney and vascular disease: toward global health equity--the Bellagio 2004 Declaration. Kidney Int Suppl 2005;98:S1-6.

-2 Henry RM, Kostense PJ, Bos G, Dekker JM, Nijpels G, Heine RJ, Bouter LM, Stehouwer CD: Mild renal insufficiency is associated with increased cardiovascular mortality: The Hoorn Study. Kidney Int 2002;62:1402-1407.

3 Sarnak MJ, Levey AS, Schoolwerth AC, Coresh J, Culleton B, Hamm LL, McCullough PA, Kasiske BL, Kelepouris E, Klag MJ, Parfrey P, Pfeffer M, Raij L, Spinosa DJ, Wilson PW; American Heart Association Councils on Kidney in Cardiovascular Disease, High Blood Pressure Research, Clinical Cardiology, and Epidemiology and Prevention: Kidney disease as a risk factor for development of cardiovascular disease: a statement from the American Heart Association Councils on Kidney in Cardiovascular Disease, High Blood Pressure Research, Clinical Cardiology, and Epidemiology and Prevention. Hypertension 2003;42:10501065.

4 Segura J, Campo C, Ruilope L: How relevant and frequent is the presence of mild renal insufficiency in essential hypertension? J Clin Hypertens (Greenwich) 2002;4:332-336.

-5 Rahman M, Brown CD, Coresh J, Davis BR, Eckfeldt JH, Kopyt N, Levey AS, Nwachuku C, Pressel S, Reisin E, Walworth C; Antihypertensive and Lipid-Lowering Treatment to Prevent Heart Attack Trial Collaborative Research Group: The prevalence of reduced glomerular filtration rate in older hypertensive patients and its association with cardiovascular disease: a report from the Antihypertensive and Lipid-Lowering Treatment to Prevent Heart Attack Trial. Arch Intern Med 2004;164:969-976. 


\section{Kidney \\ Blood Pressure Research}

\begin{tabular}{|c|c|}
\hline Kidney Blood Press Res 201 & \\
\hline $\begin{array}{l}\text { DOI: } 10.1159 / 000368480 \\
\text { Publisnea onlIne: February 07, } 2015\end{array}$ & $\begin{array}{l}\text { (c) } 2015 \text { S. Karger AG, Basel } \\
\text { www.karger.com/kbr }\end{array}$ \\
\hline
\end{tabular}

Guo et al.: Depression and Quality of Life

6 Cerasola G, Mulè G, Nardi E, Cusimano P, Palermo A, Arsena R, Guarneri M, Geraci C, Cottone S: Clinical correlates of renal dysfunction in hypertensive patients without cardiovascular complications: the REDHY study. J Hum Hypertens 2010;24:44-50.

7 Zheng L, Sun Z, Zhang X, Li J, Hu D, Sun Y: The association between glomerular filtration rate and stroke in hypertensive patients in rural areas of China. J Hypertens 2012;30:901-907.

$>8$ Viazzi F, Leoncini G, Conti N, Tomolillo C, Giachero G, Vercelli M, Deferrari G, Pontremoli R: Combined effect of albuminuria and estimated glomerular filtration rate on cardiovascular events and all-cause mortality in uncomplicated hypertensive patients. J Hypertens 2010;28:848-855.

-9 Zhang R, Zheng L, Sun Z, Zhang X, Li J, Hu D, Sun Y: Decreased glomerular filtration rate is associated with mortality and cardiovascular events in patients with hypertension: a prospective study. PLoS One 2011;6:e27359.

10 Chobanian AV, Bakris GL, Black HR, Cushman WC, Green LA, Izzo JL Jr, Jones DW, Materson BJ, Oparil S, Wright JT Jr, Roccella EJ; National Heart, Lung, and Blood Institute Joint National Committee on Prevention, Detection, Evaluation, and Treatment of High Blood Pressure; National High Blood Pressure Education Program Coordinating Committee: The Seventh Report of the Joint National Committee on Prevention, Detection, Evaluation, and Treatment of High Blood Pressure: the JNC 7 report. JAMA 2003;289:2560-2572.

11 Mancia G, De Backer G, Dominiczak A, Cifkova R, Fagard R, Germano G, Grassi G, Heagerty AM, Kjeldsen SE, Laurent S, Narkiewicz K, Ruilope L, Rynkiewicz A, Schmieder RE, Boudier HA, Zanchetti A, Vahanian A, Camm J, De Caterina R, Dean V, Dickstein K, Filippatos G, Funck-Brentano C, Hellemans I, Kristensen SD, McGregor K, Sechtem U, Silber S, Tendera M, Widimsky P, Zamorano JL, Erdine S, Kiowski W, Agabiti-Rosei E, Ambrosioni E, Lindholm LH, Viigimaa M, Adamopoulos S, Agabiti-Rosei E, Ambrosioni E, Bertomeu V, Clement D, Erdine S, Farsang C, Gaita D, Lip G, Mallion JM, Manolis AJ, Nilsson PM, O'Brien E, Ponikowski P, Redon J, Ruschitzka F, Tamargo J, van Zwieten P, Waeber B, Williams B; Management of Arterial Hypertension of the European Society of Hypertension; European Society of Cardiology: 2007 guidelines for the management of arterial hypertension: the task force for the management of arterial hypertension of the European Society of Hypertension (ESH) and of the European Society of Cardiology (ESC). J Hypertens 2007;25:1105-1187.

12 Cohen SD, Norris L, Acquaviva K, Peterson RA, Kimmel PL: Screening, diagnosis, and treatment of depression in patients with end-stage renal disease. Clin J Am Soc Nephrol 2007;2:1332-1342.

13 Kimmel PL, Cohen SD, Peterson RA: Depression in patients with chronic renal disease: where are we going? J Ren Nutr 2008;18:99-103.

14 Porter A, Fischer MJ, Brooks D, Bruce M, Charleston J, Cleveland WH, Dowie D, Faulkner M, Gassman J, Greene T, Hiremath L, Kendrick C, Kusek JW, Thornley-Brown D, Wang X, Norris K, Unruh M, Lash J: Quality of life and psychosocial factors in African Americans with hypertensive chronic kidney disease. Transl Res 2012;159:4-11.

-15 Shlipak MG, Stehman-Breen C, Fried LF, Song X, Siscovick D, Fried LP, Psaty BM, Newman AB: The presence of frailty in elderly persons with chronic renal insufficiency. Am J Kidney Dis 2004;43:861-867.

-16 Odden MC, Whooley MA, Shilpak MG: Depression, stress, and quality of life in persons with chronic kidney disease: the Heart and Soul Study. Nephron Clin Pract 2006;103:c1-7.

$\checkmark 17$ Iyasere 0, Brown EA: Determinants of quality of life in advanced kidney disease: time to screen? Postgrad Med J 2014;90:340-347.

18 Bautovich A, Katz I, Smith M, Loo CK, Harvey SB: Depression and chronic kidney disease: A review for clinicians. Aust N Z J Psychiatry 2014;48:530-541.

19 Mapes DL, Bragg-Gresham JL, Bommer J, Fukuhara S, McKevitt P, Wikström B, Lopes AA: Health-related quality of life in the dialysis outcomes and practice pattern study (DOPPS). Am J Kidney Dis 2004;44:54-60.

20 Kroenke K, Spitzer RL, Williams JB: The PHQ-9: validity of a brief depression severity measure. J Gen Intern Med 2001;16:606-613.

21 Löwe B, Kroenke K, Herzog W, Gräfe K: Measuring depression outcome with a brief self-report instrument: sensitivity to change of the Patient Health Questionnaire (PHQ-9). J Affect Disord 2004;81:61-66.

22 Manea L, Gilbody S, McMillan D: Optimal cut-off score for diagnosing depression with the Patient Health Questionnaire (PHQ-9): a meta-analysis. CMAJ 2012;184:E191-196. 


\section{Kidney \\ Blood Pressure Research}

\begin{tabular}{|c|c|}
\hline Kidney Blood Press Res 201 & \\
\hline $\begin{array}{l}\text { DOI: 10.1159/000368480 } \\
\text { Publisned onIne: February 07, } 2015\end{array}$ & $\begin{array}{l}\text { (c) } 2015 \text { S. Karger AG, Basel } \\
\text { www.karger.com/kbr }\end{array}$ \\
\hline
\end{tabular}

Guo et al.: Depression and Quality of Life

23 Skevington SM, Lotfy M, O'Connell KA; WHOQOL Group: The World Health Organization's WHOQOL-BREF quality of life assessment: psychometric properties and results of the international field trial. A report from the WHOQOL group. Qual Life Res 2004;13:299-310.

$\checkmark 24$ Development of the World Health Organization WHOQOL-BREF quality of life assessment: The WHOQOL Group. Psychol Med 1998;28:551-558.

-25 Levey AS, Stevens LA, Schmid CH, Zhang YL, Castro AF, $3^{\text {rd }}$, Feldman HI, Kusek JW, Eggers P, Van Lente F, Greene T, Coresh J; CKD-EPI (Chronic Kidney Disease Epidemiology Collaboration): A new equation to estimate glomerular filtration rate. Ann Intern Med 2009;150:604-612.

-26 Levey AS, Bosch JP, Lewis JB, Greene T, Rogers N, Roth D: A more accurate method to estimate glomerular filtration rate from serum creatinine: a new prediction equation. Modification of Diet in Renal Disease Study Group. Ann Intern Med 1999;130:461-470.

27 O'Brien E, Petrie J, Littler W, de Swiet M, Padfield PL, O'Malley K, Jamieson M, Altman D, Bland M, Atkins $\mathrm{N}$ : The British Hypertension Society protocol for the evaluation of automated and semi-automated blood pressure measuring devices with special reference to ambulatory systems. J Hypertens 1990;8:607-619.

28 Hu G, Tuomilehto J, Silventoinen K, Barengo N, Jousilahti P: Joint effects of physical activity, body mass index, waist circumference and waist-to-hip ratio with the risk of cardiovascular disease among middleaged Finnish men and women. Eur Heart J 2004;25:2212-2219.

-29 Panagiotakos DB, Pitsavos C, Chrysohoou C, Risvas G, Kontogianni MD, Zampelas A, Stefanadis C: Epidemiology of overweight and obesity in a Greek adult population: the ATTICA Study. Obes Res 2004;12:1914-1920.

- 30 Cerasola G, Mulè G, Cottone S, Nardi E, Cusimano P: Hypertension, microalbuminuria and renal dysfunction: the Renal Dysfunction in Hypertension (REDHY) study. J Nephrol 2008;21:368-373.

-31 Zhang L, Wang F, Wang L, Wang W, Liu B, Liu J, Chen M, He Q Liao Y, Yu X, Chen N, Zhang JE, Hu Z, Liu F, Hong D, Ma L, Liu H, Zhou X, Chen J, Pan L, Chen W, Wang W, Li X, Wang H: Prevalence of chronic kidney disease in China: a cross-sectional survey. Lancet 2012;379:815-822.

-32 National Kidney Foundation; K/DOQI clinical practice guidelines for chronic kidney disease: evaluation, classification, and stratification. Am J Kidney Dis 2002;39:S1-266.

-33 Kimmel PL, Peterson RA, Weihs KL, Simmens SJ, Alleyne S, Cruz I, Veis JH: Multiple measurements of depression predict mortality in a longitudinal study of chronic hemodialysis outpatients. Kidney Int 2000;57:2093-2098.

34 Suzuki R, Rygh LJ, Dickenson AH: Bad news from the brain: descending 5-HT pathways that control spinal pain processing. Trends Pharmacol Sci 2004;25:613-617.

- 35 Kessler RC, Berglund P, Demler O, Jin R, Koretz D, Merikangas KR, Rush AJ, Walters EE, Wang PS; National Comorbidity Survey Replication: The epidemiology of major depressive disorder: results from the National Comorbidity Survey Replication (NCS-R). JAMA. 2003;289:3095-3105.

-36 Kimmel PL, Patel SS, Peterson RA: Depression in African-American patients with kidney disease. J Natl Med Assoc 2002;94:925-1035.

- 37 Fischer MJ, Kimmel PL, Greene T, Gassman JJ, Wang X, Brooks DH, Charleston J, Dowie D, Thornley-Brown D, Cooper LA, Bruce MA, Kusek JW, Norris KC, Lash JP; AASK study group: Sociodemographic factors contribute to the depressive affect among African Americans with chronic kidney disease. Kidney Int 2010;77:1010-1019.

- 38 Ricardo AC, Fischer MJ, Peck A, Turyk M, Lash JP: Depressive symptoms and chronic kidney disease: results from the National Health and Nutrition Examination Survey (NHANES) 2005-2006. Int Urol Nephrol 2010;42:1063-1068.

-39 Burg MM, Barefoot J, Berkman L, Catellier DJ, Czajkowski S, Saab P, Huber M, DeLillo V, Mitchell P, Skala J, Taylor CB; ENRICHD Investigators: Low perceived social support and post-myocardial infarction prognosis in the enhancing recovery in coronary heart disease clinical trial: the effects of treatment. Psychosom Med 2005;67:879-888. 